\title{
Process intensification applied to spent nuclear fuel reprocessing: an alternative flowsheet using small channels
}

\author{
Davide Bascone*, Panagiota Angeli, Eric S. Fraga \\ Centre for Process Systems Engineering, Department of Chemical Engineering, University \\ College London (UCL), London WC1E 6BT, United Kingdom
}

\begin{abstract}
Commercial plants for spent nuclear fuel reprocessing rely on the Plutonium Uranium Extraction (PUREX) process, based on traditional liquid-liquid extraction technologies. In this paper, an alternative flowsheet for spent nuclear fuel reprocessing is proposed, based on small-scale extractors to overcome some of the issues related to the conventional technologies, such as solvent degradation, size and nuclear criticality control. The main goal of the process is to preclude the risk of nuclear proliferation, hence a mixed uranium/plutonium oxide is produced instead of pure plutonium.

A superstructure optimisation based framework has been used to identify a process with several benefits over the conventional process. Novel flow configurations and organic solvent composition have been investigated. A large number of components and chemical reactions are included in the framework. The resulting model is a mixed integer nonlinear optimisation problem, implemented in the General Algebraic Modeling System (GAMS).

The most promising flowsheet identified is more cost effective than the conventional one. Furthermore, advantages in terms of safety and separation efficiency have been achieved. It was found that increasing the inner diameter of the small channels up to $2.5 \mathrm{~mm}$, as well as increasing the tributyl phosphate fraction in the organic solvent, are advantageous.
\end{abstract}

\footnotetext{
${ }^{*}$ Corresponding author
} 
Keywords: Liquid-liquid extraction; small channels; spent

nuclear fuel reprocessing; optimisation; process design.

\section{Introduction}

Spent nuclear fuel (SNF) reprocessing is a crucial step to recover uranium and plutonium from nuclear waste and reduce its volume and long-term radiotoxiticy [1]. Today, SNF reprocessing is achieved through the Plutonium 5 Uranium Extraction (PUREX) process, which consists of two or more liquidliquid extraction cycles to separate $\mathrm{U}$ and $\mathrm{Pu}$ from the SNF [2, 3]. The SNF is dissolved in a nitric acid solution. In the aqueous feed, $\mathrm{U}$ exists as $\mathrm{U}(\mathrm{VI})$, in the form of $\mathrm{UO}_{2}^{2+}$, whilst $\mathrm{Pu}$ exists as $\mathrm{Pu}(\mathrm{IV})$, in the form of $\mathrm{Pu}^{4+}$. The PUREX process exploits the selectivity of Tributyl Phosphate (TBP) to produce pure U and pure $\mathrm{Pu}$, according to the following reactions:

$$
\begin{gathered}
U O_{2}^{+2}+2 \mathrm{NO}_{3}^{-}+2 \mathrm{TBP} \rightleftharpoons\left[\mathrm{UO}_{2}\left(\mathrm{NO}_{3}\right)_{2}\right] \cdot 2 \mathrm{TBP} \\
P u^{+4}+4 \mathrm{NO}_{3}^{-}+2 \mathrm{TBP} \rightleftharpoons\left[\mathrm{Pu}\left(\mathrm{NO}_{3}\right)_{4}\right] \cdot 2 \mathrm{TBP}
\end{gathered}
$$

The recovery of pure plutonium was the goal of the Manhattan Project, when this process was invented. Hence, this process poses nuclear proliferation risks. Today, after numerous liquid-liquid extraction operations to separate and purify $\mathrm{Pu}$, the pure $\mathrm{Pu}$ product is mixed again with $\mathrm{U}$ to produce a mixed oxide (MOX) fuel. It is mainly for these reasons that several new flowsheets have been suggested in the last years, as the next generations of the PUREX process. Basically, the goal is to avoid a pure $\mathrm{Pu}$ stream by either producing mixed $\mathrm{Pu} / \mathrm{U}$ oxide or keeping a fraction of some components, such as $\mathrm{Np}$, within the $\mathrm{Pu}$ stream [4, 5].

One of the most interesting flowsheets to preclude pure $\mathrm{Pu}$ product is the socalled COEX (Combined U and Pu Extraction) process [4. The co-extraction of both $\mathrm{U}$ and $\mathrm{Pu}$ also leads to a better MOX quality, when compared with the current MOX manufacturing process. This is due to the improved homogeneity 
of $\mathrm{U}$ and $\mathrm{Pu}$ distribution within the oxide [4. A simplified flowsheet of the COEX process is shown in Figure 1 [4.

The COEX process has the same first section as the PUREX process, i.e. the codecontamination section, where $\mathrm{U}$ and $\mathrm{Pu}$ are separated from most of the SNF. The product stream of the codecontamination section, which is an organic phase containing $\mathrm{U}, \mathrm{Pu}, \mathrm{HNO}_{3}$ and very small amounts of contaminants (in 30 particular $\mathrm{Tc}, \mathrm{Np}, \mathrm{Zr}$ and $\mathrm{Ru}$ ) undergoes a first stripping step. This step is called "co-stripping". The goal is to strip simultaneously U and Pu from the organic stream. However, the $\mathrm{Pu} / \mathrm{U}$ ratio in the organic stream leaving the codecontamination section is too low to produce suitable MOX fuel. The idea is then to strip all $\mathrm{Pu}$ and only a small fraction of $\mathrm{U}$ to achieve an appropriate $\mathrm{Pu} / \mathrm{U}$ 35 ratio for MOX fabrication, typically around $10 \%$. The affinity of TBP is low for +5 and +3 oxidation states [4. Hence, if $\mathrm{Pu}(\mathrm{IV})$ is reduced to $\mathrm{Pu}(\mathrm{III})$, which is not very extractable, it is possible to selectively back extract $\mathrm{Pu}$ as $\mathrm{Pu}(\mathrm{III})$. Typical reductants used in the PUREX process are U(IV) and hydroxylamine nitrate (HAN). Also, since in nitric acid solution $\mathrm{Pu}(\mathrm{III})$ oxidation to $\mathrm{Pu}(\mathrm{IV})$ occurs if $\mathrm{HNO}_{2}$ is present, typically hydrazine nitrate $\mathrm{N}_{2} \mathrm{H}_{4} \cdot \mathrm{HNO}_{3}$ is used in the aqueous phase as nitrite scavenger to stop further $\mathrm{Pu}$ (III) oxidation.

The use of small channels for liquid-liquid extraction have been widely investigated in the last years $[6,7,8,9,10,11,12]$. A common flow pattern in small channels which forms under a wide range of conditions is segmented flow, where one phase forms elongated drops, also called "plugs", separated by continuous phase slugs. In this pattern, the interfacial area and then the mass transfer are enhanced, thus reducing plant size. This concept is known as "process intensification" [13, 14, 15, 16, 17, 18. An extensive review of the development of process intensification technologies is given by Tian et al. [19.

${ }_{50}$ Traditional liquid-liquid contactors used in the nuclear industry are mixersettlers and pulsed columns. Both technologies require large residence times, which lead to solvent degradation, with the consequent need for a solvent regeneration and cleanup section. Mixer-settlers may also pose nuclear criticality issues [20]. The use of centrifugal extractors, despite being the most promising 


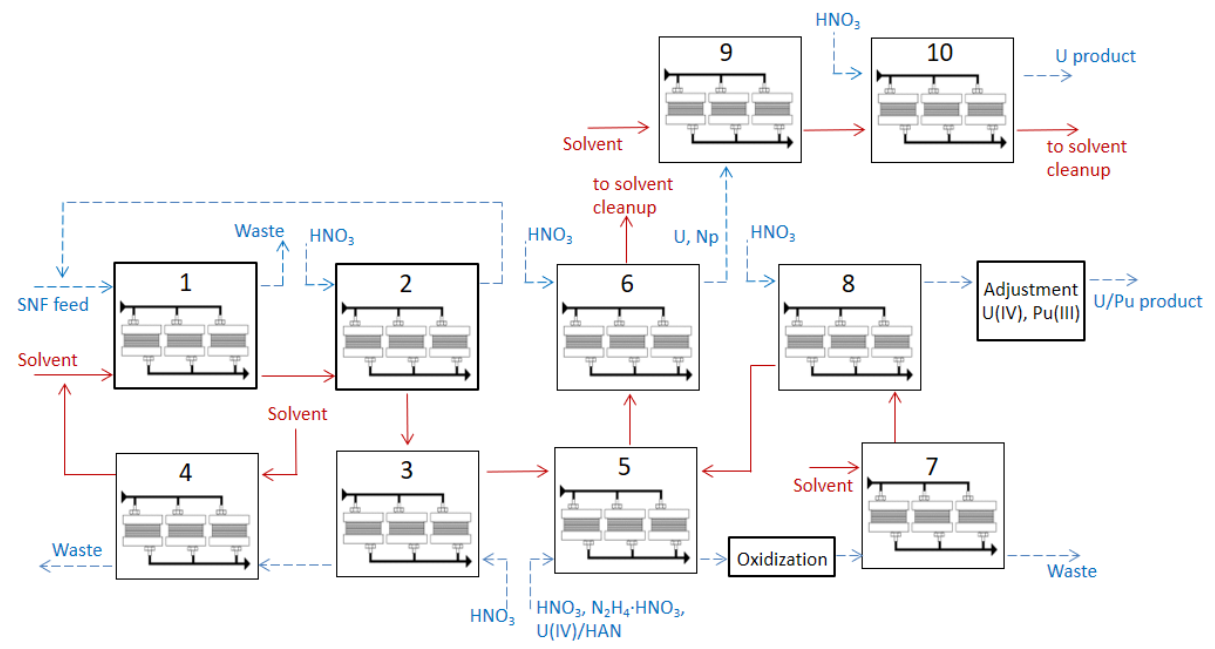

Figure 1: Simplified flowsheet of the COEX process 4]. The unit operations are the following: main extraction (step 1), Ru and Zr scrubbing (2), Tc scrubbing (3), complementary extraction (4), U/Pu co-stripping (5), U stripping (6), U/Pu extraction (7), U/Pu stripping (8), U extraction (9) and a second U stripping (10). In the oxidation step, Pu and U are oxidised to improve their extraction. Steps 1-4 represent a simplified codecontamination section, steps 9-10 the $U$ purification section in the second cycle. Blue dashed streams refer to aqueous streams, red continuous streams refer to organic streams.

conventional technology, is limited [21, 20], probably due to the low tolerance to solids and their complex maintenance which requires periodical replacement of the motor and/or the rotor [21. Many of these drawbacks may be overcome with the use of intensified technologies, which makes possible new processing routes and design alternatives. Solvent residence time can be significantly reduced. Also, the plant size and then the volume of hazardous materials involved may be reduced, with important improvements for safety and nuclear criticality considerations. Furthermore, hydrodynamics are more easily described and controlled in small scale contactors.

In this paper, a novel flowsheet for the co-extraction of $\mathrm{U}$ and $\mathrm{Pu}$ in the SNF reprocessing is proposed. The design is made possible by the use of intensified small scale extractors. The use of the intensified extractors allows different 
design concepts to be implemented in the flowsheet, such as the use of different nitric acid streams between the various stages in back extraction and the use of different concentrations of TBP. As a result, the number of unit operations can be reduced compared with the COEX process (Figure 1), improving safety, economics and equipment footprint.

A superstructure model-based optimisation approach is used to identify the best process design. A superstructure incorporates all alternative flowsheets of interest, from which the best one can be found. It is a common and effective tool to formulate flowsheet synthesis problems, often as mixed-integer nonlinear programming problems $[22,23,24,25,26,27$.

A mathematical model has been developed to describe all phenomena in the processes involved, in particular the mass transfer and redox reactions required to evaluate the performance of all potential flowsheets included in the superstructure. The resulting model, posed as an optimisation problem, is a mixed integer nonlinear problem, implemented in the General Algebraic Modeling System (GAMS) 28.

The remainder of the paper is organised as follows. The superstructure framework including potential routes for the novel SNF reprocessing is described in section 2. The optimisation design problem developed to identify the best flowsheet is shown in section 3 . The description of the mathematical models needed to investigate the SNF reprocessing flowsheet using small channels is given in this section. The results are presented in section 4 Impacts of the modelling assumptions are discussed, as well as the potential advantages and disadvantages of the flowsheet proposed using the small-scale extractors. Finally, the paper concludes with a general discussion of this work and future developments.

\section{The superstructure flowsheet}

In this section, the proposed superstructure is discussed in detail. The process flowsheet superstructure, which contains all considered alternatives of the 
process network, is shown in Figure 2. Below, the main characteristics are described.

\subsection{Unit operations}

The superstructure proposed involves a total of 5 steps. Each step represents a unit operation:

1. the main extraction, where $\mathrm{U}, \mathrm{Pu}$ and a small fraction of the contaminants are extracted from the feed;

2. the scrubbing of $\mathrm{Zr}, \mathrm{Ru}$ and $\mathrm{Tc}$ from the organic phase;

3. the complementary extraction. This step might not be used if the whole aqueous stream leaving step 2 is recycled to step 1 . The recycle ratio $\chi$ is a design variable, which varies from 0 , the case of no recycle to step 1 , to 1 , the case of no aqueous stream fed to step 3 ;

4. the $\mathrm{U} / \mathrm{Pu}$ co-stripping, where $\mathrm{Pu}(\mathrm{IV})$ is reduced to $\mathrm{Pu}(\mathrm{III})$ and back extracted, or stripped, with a small portion of $\mathrm{U}$ for a mixed $\mathrm{Pu} / \mathrm{U}$ product;

The use of step 3 represents one of the potential alternatives embedded in the superstructure, as well as the use of the aqueous waste streams in step 2, the inter-stage aqueous streams in step 4 and the use of either one or two fresh solvent streams.

Small amounts of TBP can be stripped by nitric acid solutions. Typically, unit operations are employed in reprocessing plants to recover the stripped organic solvent, using the organic diluent [4. However, the TBP solubility in nitric acid is small and has been neglected in this work, hence these unit operations are not included in the superstructure flowsheet.

Steps 1-3 represent an alternative to the current codecontamination section, as discussed in [29]. The recycle of the organic stream from step 4 to step 1 is a common approach in the modern commercial plants [4. The aqueous stream leaving step 1 is a high-level waste, which undergoes vitrification or solidification, then storage and finally disposal. In all the other waste streams 


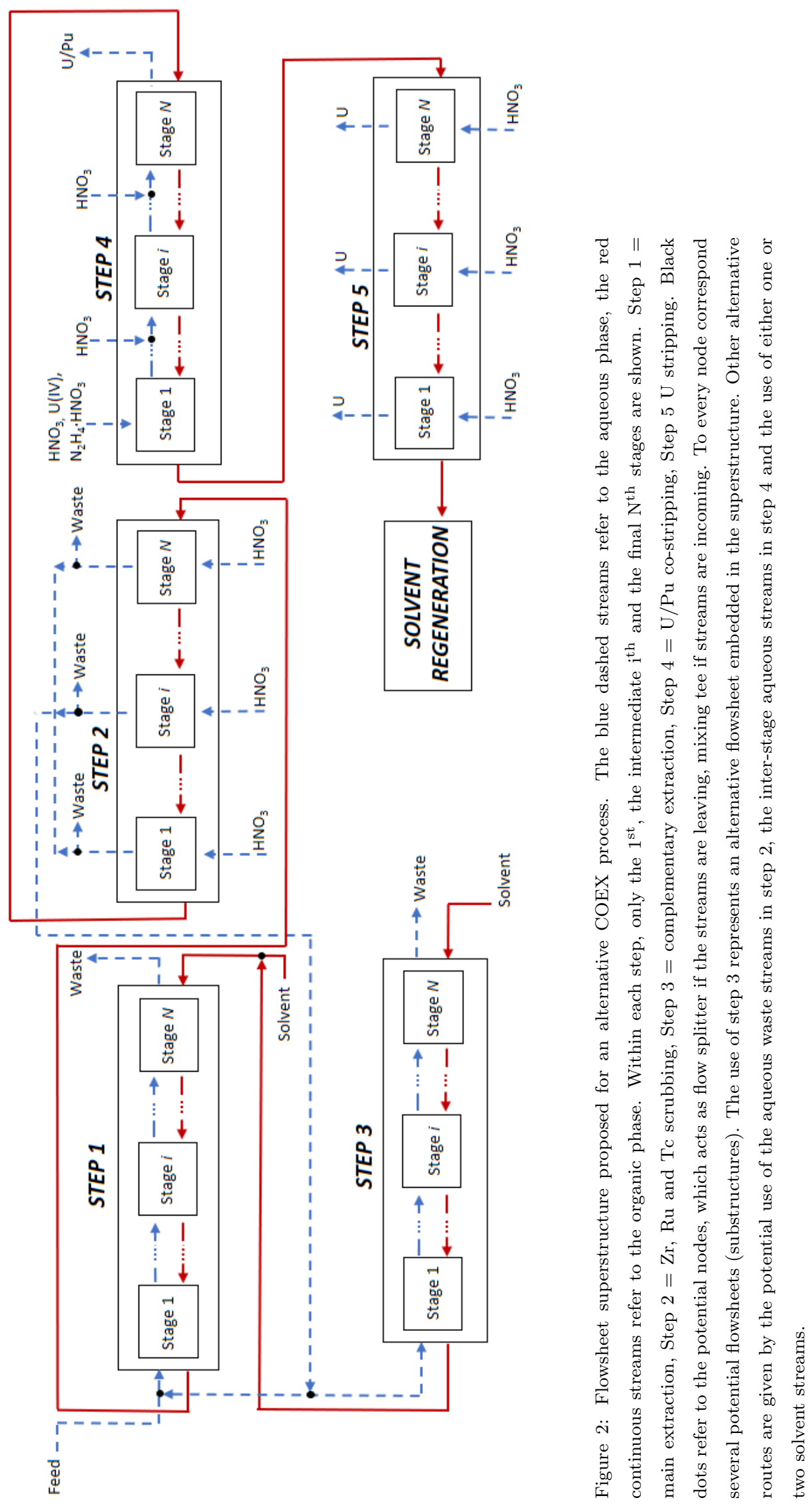


of the flowsheet, the amount of highly active material is significantly lower than the aqueous stream leaving step 1, therefore their handling and disposal is less challenging.

Compared with the COEX process as presented by Herbst et al. [4] and shown in Figure 1, the flowsheets embedded in this superstructure involve less extraction steps, no second cycle for $U$ purification, no adjustment step to correct the $\mathrm{Pu} / \mathrm{U}$ ratio and no recycle streams after step 3. According to the model, this simplified flowsheet can meet the industrial requirements, in terms of extraction efficiencies and product qualities, if high decontamination factors DF (defined as the ratio between the amount of contaminant in the feed and the one in the product stream) are obtained in steps 1-3. Hence, no furher liquidliquid extraction operations for purification of $\mathrm{U}$ (the second cycle) and MOX products are required.

\subsection{Small scale extractor}

The intensified extractors are single channels with diameters in the scale of a millimetre. The flow within the channels is co-current. To drive the separation, a multi-stage design can be used. Counter-current or cross-flow configurations can be applied to the stream arrangement outside the small channels. To increase the throughput, many channels are used in parallel. For effective and uniform flow distribution, suitable manifolds are needed. Here, a comb-like manifold structure with four levels is considered [30. The $1^{\text {st }}$ level consists of the small channel extractors. This is the only level where two-phase flow occurs and it is shared by the two manifolds (one for each phase) through a mixing junction, for example a $\mathrm{T}$ or a $\mathrm{Y}$ junction. At the end of the small channels, the two phases are separated by a two-phase flow separator [31. From the $2^{\text {nd }}$ level up, each level is the distributor and then the collector of the single-phase flow respectively to and from the sub-level, e.g. the $2^{\text {nd }}$ level distributes and then collects the single-phase flows to/from the $1^{\text {st }}$ level, the $3^{\text {rd }}$ level to/from the $2^{\text {nd }}$ level and so on. A sketch of the comb-like manifold considered is illustrated in Figure 3 . 


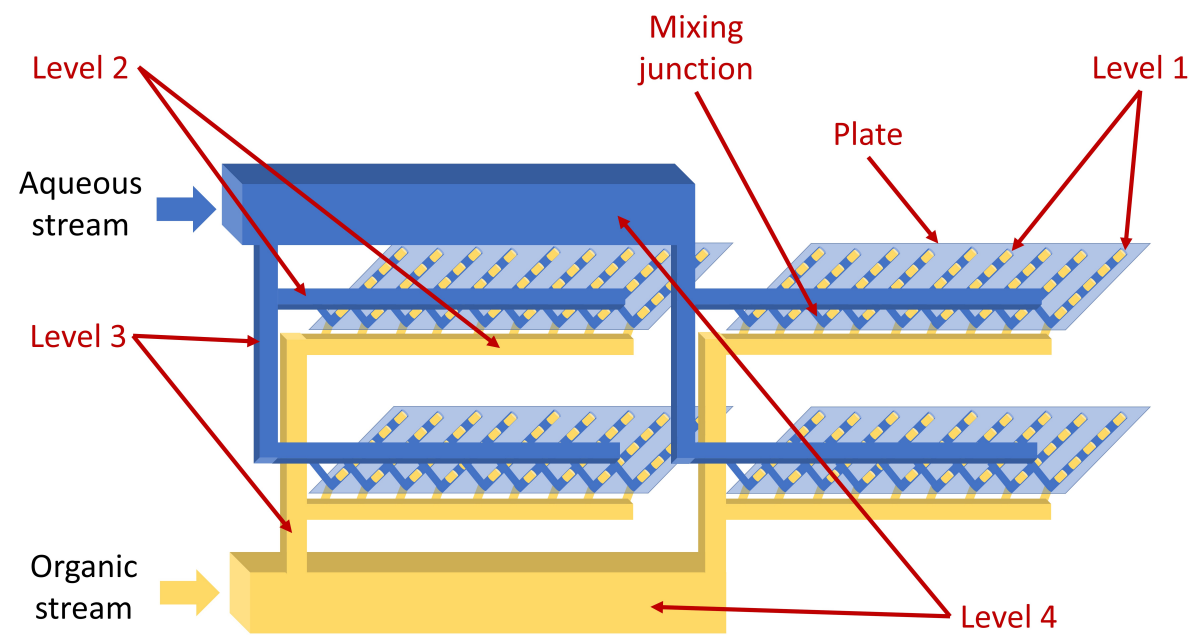

Figure 3: Sketch of the comb-like distributor suggested for the small-scale technology. The four levels of the distributor are shown. The $1^{\text {st }}$ level consists of the small-scale extractors, which are shared by the two manifolds through mixing junctions. The small channels are placed on a plate. In this example, hydrophobic small channels are assumed (yellow organic plugs dispersed in the blue continuous aqueous phase). In the $1^{\text {st }}$ level nine channels, also called "elements", are shown. The $2^{\text {nd }}$ level distributes the single-phase flows to the small scale extractors, the $3^{\text {rd }}$ level distributes the single-phase flows to the $2^{\text {nd }}$ level. The $4^{\text {th }}$ level is the largest distributor, where the single-phase flows, from the previous step or stage, enter the manifold. For each phase, two elements are shown for both $2^{\text {nd }}$ and $3^{\text {rd }}$ levels, whereas the $4^{\text {th }}$ level always consists of a single element. Hence, a total of $9 \times 2 \times 2 \times 1=36$ small channels are arranged in this example. The collectors have the same design as the distributors. 


\subsection{Flow configurations}

Important design variables are the organic flow rate, the TBP concentration in the organic streams, the aqueous phase flow rates used in the back extraction units and all their nitric acid concentrations. These variables significantly affect hydrodynamics, equilibria and mass transfer.

In stripping operations, it may be advantageous to use a different nitric acid concentration and/or different aqueous phase flow rates at each stage. This is possible when a cross-flow configuration is used, whilst it is not possible when a counter-current configuration is employed. $\mathrm{HNO}_{3}$ can shift equilibria and the cross-flow configuration can be beneficial especially in the scrubbing section, where $\mathrm{Ru}$ and $\mathrm{Zr}$ can be easily stripped by dilute $\mathrm{HNO}_{3}$ solution whilst Tc stripping requires concentrated $\mathrm{HNO}_{3}$ solution. Also, the use of fresh nitric acid solution at each stage allows operation with larger driving forces for mass transport (since the entering aqueous stream does not contain any metals). The cross-flow design is applied to steps 2 and 5 of the flowsheet shown in Figure 2

On the contrary, the cross-flow configuration is not applied to the extraction steps 1 and 3 as this would involve fresh organic flow rates at each stage and, therefore, significantly high solvent-related costs.

The $\mathrm{Pu} / \mathrm{U}$ co-stripping, step 4, is different from the other scrubbing/stripping steps (2 and 5$)$ because of the presence of the reductant in the inlet aqueous stream. Fresh $\mathrm{HNO}_{3}$ solutions containing $\mathrm{U}(\mathrm{IV})$ cannot be fed to each stage in this unit operation: the final $\mathrm{U}$ content in the $\mathrm{Pu} / \mathrm{U}$ product would be too high, whilst with lower amount of fresh U(IV) per stage the reaction rate would not be high enough to complete the $\mathrm{Pu}(\mathrm{IV})$ reduction into $\mathrm{Pu}(\mathrm{III})$. To investigate the possibility of different $\mathrm{HNO}_{3}$ concentrations and/or aqueous flow rates in this step, the use of additional $\mathrm{HNO}_{3}$ solution (without reductant) between the stages will be considered. In this way, the reductant, which is fed only to the first stage, can have the necessary residence time to allow $\mathrm{Pu}$ reduction and stripping with high efficiency, whilst the nitric acid solution and flow rates can be adjusted in some stages, if beneficial, to vary hydrodynamics, reaction kinetics and equilibrium relationships. 
The psuedo cross-flow configuration and the potential inter-stage streams in step 4 increase the number of design variables and hence the size of the model, since different flow rates and manifold designs must be allowed even for the same step.

190 fraction improves back extraction.

All unit operations in Figure 2 are solved simultaneously. The overall number of equations is approximately 450,000; the discrete variables are 47 . The 
optimisation model is implemented in GAMS. The solver used for this optimisation problem is a local optimiser for MINLP, the SBB solver (maximum relative gap, OPTCR value in GAMS, set to 1\%) 28]. The other MINLP solvers were not able to find feasible solutions. Below, the optimisation model used to identify the superstructure-based process design is presented in detail. Description and motivation of objective functions chosen and both inequality and equality constraints (i.e. the process model using small channels) are given.

\subsection{Objective}

The process has been optimised according to an economic criterion, to minimise the total annualised cost $T A C$ :

$$
T A C=O p E x+A C a p E x
$$

225 where $O p E x$ is the operating expenditure and $A C a p E x$ is the annualised capital expenditure. This objective function incorporates information regarding size $(A C a p E x)$ and usage of solvent $(O p E x)$. The capital costs, estimated from current prices of channels and mixing junctions, represent the cost of small extractors and manifolds 32 . The operating costs are the pumping costs. Due to the limited number of unit operations considered in the superstructure flowsheet and the short residence time of the solvent within the small-scale extractors, the solvent makeup is neglected. Although the results will be a function of the assumed costs mentioned above, the methodology allows for alternative cost models and assumptions.

A payout time of 5 years and a $5 \%$ interest rate have been considered to calculate the annual costs. In the previous work, similar to the first part of this flowsheet and using the small-scale intensified units, it was observed that the payout time, in a reasonable range, did not markedly affect the choice of the optimal design [32.

\subsection{Inequality constraints and bounds}

The inequality constraints are described in Table1. The first five constraints in the table, i.e. the one regarding $U$ concentration in the aqueous stream 
leaving step 1 , the recovery of $\mathrm{U}$ and $\mathrm{Pu}$ from step 1 to step 3 (the so-called "codecontamination section") and decontamination factors DF of $\mathrm{Zr}$ and $\mathrm{Ru}$ are typical industrial requirements. DF of Tc has been increased to 50, to allow higher purities of products (a typical value of this DF is between 3 and 10 [4]).

The mass transfer model, described below in section 3.3.2, is valid for segmented flow. In order to ensure segmented flow, the range of the aqueous to organic flow rate ratios $q$ reported by Kashid and Agar [9], for water-cyclohexhane and capillary diameters of $1 \mathrm{~mm}$ at a total superficial velocity of $2 \mathrm{~cm} / \mathrm{s}$ (which is approximately the velocity expected in the process design), has been used. This range has been used due to the limited data on the flow behaviour of the nitric acid solution-TBP/kerosene mixture in small channels.

The upper bound used for the superficial velocity of the two-phase flow is lower than the maximum velocity reported by Kashid and Agar for segmented flow. The effective multiplication factor $k_{\text {eff }}$ has to be lower than 0.95 to ensure nuclear subcriticality.

The maximum number of elements in the first level of the manifold $\left(N_{\text {level } 1}^{\text {elem }}\right)$ and the minimum resistance ratio between level 2 and level 1 ( $\left.r_{\text {level } 2}\right)$ are set to, respectively, 70 and $10^{4}$. These two inequality constraints, in addition to a laminar regime $(R e \leq 2000)$ as suggested by Commenge et al. [33], are required to guarantee a flow maldistribution lower than approximately $10 \%$ and replace the nonlinear empirical relationships to predict the flow maldistribution (as function of the number of channels in each level of the manifold and the hydraulic resistance ratio $r$ ) used in the previous work 32. With this simplifying assumption, the actual value of the flow maldistribution is no longer possible to predict but it ensures that it is lower than $10 \%$, i.e. the upper limit assumed here.

A larger upper bound, compared with the previous works [34, 32] is used for the channel diameter, $2.5 \mathrm{~mm}$ rather than $2 \mathrm{~mm}$. The few works available in channel diameters of $3 \mathrm{~mm}$ show high mass transfer coefficients [35]. In a potential industrial application of this technology, it will be crucial to identify the largest diameter possible, to reduce the number of channels and simplify 
the manifold design. The effect of the upper limit on the process has been investigated in this paper. In particular, the goal is to explore the impact of a potential increase in the channel diameter, up to $25 \%$, on the process design and performance. The mass transfer model used has never been validated for this value. Although some uncertainty is expected, due to the extrapolation of the volumetric mass transfer coefficient $k_{L} a$, the optimisation model may still provide valuable insights.

Table 1: Inequality constraints of the optimisation problem.

\begin{tabular}{|c|c|}
\hline Inequality constraints & Comment \\
\hline $\operatorname{Rec}_{\mathrm{U}}^{\text {Steps 1-3 }} \geq 0.99$ & Minimum uranium recovery \\
\hline $\operatorname{Rec}_{\mathrm{Pu}}^{\text {Steps }}{ }^{1-3} \geq 0.99$ & Minimum plutonium recovery \\
\hline$[\mathrm{U}]_{\text {aq,out }}^{\text {Step } 1} \leq 1.68 \mathrm{M}$ & $\begin{array}{l}\text { Maximum typical uranium concentration in } \\
\text { the high level waste from step } 1\end{array}$ \\
\hline $\mathrm{DF}_{\mathrm{Zr}} \geq 10^{4}$ & Typical requirement [4] \\
\hline $\mathrm{DF}_{\mathrm{Ru}} \geq 10^{4}$ & Typical requirement 4 ] \\
\hline $\mathrm{DF}_{\mathrm{Tc}} \geq 50$ & Increased from typical requirement [4] \\
\hline$E_{\mathrm{Pu}}^{\text {Step }}{ }^{4} \geq 0.99$ & $\mathrm{Pu}$ extraction efficiency required \\
\hline$E_{\mathrm{U}}^{\text {Step } 5} \geq 0.99$ & U extraction efficiency required \\
\hline$[\mathrm{Pu}]_{\text {aq, out }}^{\text {Step } 4} /[\mathrm{U}]_{\text {aq, out }}^{\text {Step }}=10 \%$ & MOX concentration required \\
\hline $0.16 \leq q \leq 5$ & segmented flow conditions 9 ] \\
\hline$k_{e f f} \leq 0.95$ & Nuclear sub-criticality \\
\hline$N_{\text {level } 1}^{\text {elem }} \leq 70$ & To ensure good flow distribution \\
\hline$r_{\text {level } 2} \geq 1 \times 10^{4}$ & To ensure good flow distribution \\
\hline$R e \leq 2000$ & Laminar flow \\
\hline
\end{tabular}

\subsection{Modelling of intensified extraction in small channels}

The system involves 15 species: two forms of uranium, two forms of plutonium, two forms of neptunium, ruthenium, zirconium, technetium, two nitric acid complexes in the organic stream, nitrous acid, TBP, hydrazine nitrate and 

3.3 .1

To reduce the computational effort, because of the number of highly nonlinear equations, some simplifying assumptions have been made. Concentrations of $\mathrm{Zr}$ and $\mathrm{Ru}$, considering the very high decontamination factors achieved in the first part of the flowsheet (steps 1-3), are expected to be extremely low in the organic stream leaving step 4 (lower than $1 \times 10^{-4} \mathrm{~mol} \mathrm{~m}^{-3}$ ) and can be neglected in step 5, to simplify the calculations. The formation of $\mathrm{Np}(\mathrm{IV})$, in the form of $\mathrm{Np}^{4+}$, is negligible in the range of $\mathrm{HNO}_{3}$ concentrations expected [32, 36. Hence, to simplify the calculations, the concentration of $\mathrm{Np}(\mathrm{IV})$ is neglected in this work.

Assuming plug flow conditions within the separator channels, the mass balance of each component in each phase is given by Eq. 4 .

$$
-v_{k} \frac{d C_{i, k}}{d L}-k_{L} a\left(C_{i, k}-C_{i, k}^{e q}\right)+\sum R_{i, k} \varphi=0
$$

where $\sum R_{i, k} \varphi$ is the sum of all chemical reactions involving the component $i$ in the phase $k$. The calculation of the volumetric mass transfer coefficient $k_{L} a$ is discussed in section 3.3.2 A fourth order Runge-Kutta method, with 50 grid points, was used to convert Eq. 4 into a set of algebraic equations.

Pressure drop of the two-phase flow in the two-phase channels has been estimated according to Kashid and Agar, considering both frictional and interfacial contributions [9]. Local and frictional pressure losses along the manifolds has been calculated, as well. The mathematical model developed in a previous work 32 has been used. However, the latter does not include all the components considered in this work, namely $\mathrm{Pu}(\mathrm{III}), \mathrm{U}(\mathrm{IV}), \mathrm{HAN}$ and $\mathrm{N}_{2} \mathrm{H}_{4} \cdot \mathrm{HNO}_{3}$. Hence, new correlations to describe thermodynamic relationships and chemical reactions have been included in the extended model. The full set of equations and 


\subsubsection{Chemical reactions}

In the flowsheet investigated, a key role in the process is played by the reduction of $\mathrm{Pu}(\mathrm{IV})$ to $\mathrm{Pu}(\mathrm{III})$, hence a reductant and several redox reactions, involving also $\mathrm{U}$ and $\mathrm{Np}$, must be investigated. Both typical reductants in the SNF reprocessing, U(IV) and HAN, have been considered in the model, so they can be compared. Also, a nitrite scavenger and its $\mathrm{HNO}_{2}$ consumption have been included. A total of 12 chemical reactions, some of which happen in both phases, are considered (see Table 2 and Table 10 in Appendix B).

\subsubsection{Mass transfer}

In [32, the overall volumetric mass transfer coefficient was calculated as suggested by Kashid et al. [1] for segmented flow:

$$
k_{L} a=0.88 \frac{v_{m i x}}{L} C a^{-0.09} R_{m i x}^{-0.09}\left(\frac{D}{L}\right)^{-0.1}
$$

In all previous investigations, the optimal values of diameter $D$ and length

Table 2: Chemical reactions included in the problem.

\begin{tabular}{rll}
\hline No. & Reaction & Phase \\
\hline (5) & $2 \mathrm{NpO}_{2}^{+}+\mathrm{NO}_{3}^{-}+3 \mathrm{H}^{+} \rightleftharpoons 2 \mathrm{NpO}_{2}^{2+}+\mathrm{HNO}_{2}+\mathrm{H}_{2} \mathrm{O}$ & Both \\
$(6)$ & $2 \mathrm{Pu}^{4+}+2 \mathrm{NH}_{3} \mathrm{OH}^{+} \rightarrow 2 \mathrm{Pu}^{3+}+\mathrm{N}_{2}+2 \mathrm{H}_{2} \mathrm{O}$ & Aq. \\
(7) & $2 \mathrm{NH}_{3} \mathrm{OH}^{+}+\mathrm{HNO}_{2} \rightarrow \mathrm{N}_{2} \mathrm{O}+2 \mathrm{H}_{2} \mathrm{O}+\mathrm{H}^{+}$ & Aq. \\
(8) & $2 \mathrm{NpO}_{2}^{2+}+2 \mathrm{NH}_{3} \mathrm{OH}^{+} \rightarrow 2 \mathrm{NpO}_{2}^{+}+4 \mathrm{H}^{+}+\mathrm{N}_{2}+2 \mathrm{H}_{2} \mathrm{O}$ & Aq. \\
(9) & $2 \mathrm{Pu}^{4+}+\mathrm{U}^{4+}+2 \mathrm{H}_{2} \mathrm{O} \rightarrow \mathrm{Pu}^{3+}+\mathrm{UO}_{2}^{2+}+4 \mathrm{H}^{+}$ & Both \\
(10) & $2 \mathrm{NpO}_{2}^{2+}+\mathrm{U}^{4+}+2 \mathrm{H}_{2} \rightarrow 2 \mathrm{NpO}_{2}^{+}+\mathrm{UO}_{2}^{2+}+4 \mathrm{H}^{+}$ & Aq. \\
$(11)$ & $2 \mathrm{NpO}_{2}^{+}+\mathrm{U}^{4+}+4 \mathrm{H}^{+} \rightarrow 2 \mathrm{~Np}^{4+}+\mathrm{UO}_{2}^{2+}+2 \mathrm{H}_{2} \mathrm{O}$ & Aq. \\
(12) & $2 \mathrm{NpO}_{2}^{2+}+2 \mathrm{~N}_{2} \mathrm{H}_{5}^{+} \rightarrow \mathrm{NpO}_{2}^{+}+\mathrm{N}_{2}+2 \mathrm{H}^{+}+2 \mathrm{NH}_{4}$ & Aq. \\
(13) & $2 \mathrm{Pu}^{4+}+2 \mathrm{~N}_{2} \mathrm{H}_{5}^{+} \rightarrow 2 \mathrm{Pu}^{3+}+2 \mathrm{NH}_{4}+\mathrm{N}_{2}+2 \mathrm{H}^{+}$ & Aq. \\
(14) & $\mathrm{HNO}_{2}+\mathrm{N}_{2} \mathrm{H}_{5}^{+} \rightarrow \mathrm{HN}_{3}+2 \mathrm{H}_{2} \mathrm{O}+\mathrm{H}^{+}$ & Aq. \\
(15) & $\mathrm{U}^{4+}+\mathrm{NO}_{3}^{-}+2 \mathrm{H}_{2} \mathrm{O} \rightarrow \mathrm{UO}_{2}^{2+}+\mathrm{HNO}_{3}+\mathrm{H}^{+}$ & Both \\
(16) & $3 \mathrm{Pu}^{3+}+\mathrm{H}^{+}+\mathrm{NO}_{3}^{-} \rightarrow 3 \mathrm{Pu}^{4+}+\mathrm{NO}^{+} 2 \mathrm{H}_{2} \mathrm{O}$ & Aq.
\end{tabular}


$L$, both design variables in the economic optimisation, were respectively the upper $(0.2 \mathrm{~cm})$ and the lower $(10 \mathrm{~cm})$ bounds [34, 32]. The superficial velocity $v_{m i x}$ achieved has been, approximately, $0.02 \mathrm{~m} \mathrm{~s}^{-1}$ in most of the stages. In this paper, a first order Taylor series expansion is used to linearise Eq. 17 around the aforementioned values of $v$ and the upper bound for $D$, while $L$ has been assumed constant and equal to its lower bound. The resulting linearised equation of the $k_{L} a$, as function of only velocity $v$ and diameter $D$, is given by:

$$
\begin{aligned}
k_{L} a(v, D)= & \left.k_{L} a\right|_{E q[17}\left(v_{0}, D_{0}\right)+\frac{\left.\delta k_{L} a\right|_{E q[17}}{\delta v}\left(v_{0}, D_{0}\right)\left(v-v_{0}\right)+ \\
& +\frac{\left.\delta k_{L} a\right|_{E q[17}}{\delta D}\left(v_{0}, D_{0}\right)\left(D-D_{0}\right)
\end{aligned}
$$

where $v_{0}$ is $0.02 \mathrm{~m} \mathrm{~s}^{-1}, D_{0}$ is the upper bound used for the diameter.

Hence, only variations of $v$ and $D$ are included in the calculation of the $k_{L} a$. This linearisation simplifies the calculations. The motivation is to investigate contactors to increase the flow rate in each channel and simplify the manifolds. The lower bound of the channel length is the lowest used in the literature 8 , 9. 10, 11]). From an industrial point of view, it is more likely that the channel length will be increased, to provide further residence time (unless it is essential for $\mathrm{Np}$ control), rather than decreased.

Eq. 18, compared to the nonlinear Eq. 17 predicts small difference in $k_{L} a$ values over a large range of velocity and diameter: for equal $L$, the linearised equation leads to an overestimation in the $k_{L} a$ of approximately $4 \%$ if the velocity is halved and an underestimation of $4 \%$ if the diameter is halved.

To calculate $\left.k_{L} a\right|_{E q[17}\left(v_{0}, D_{0}\right)$, Re and $C a$ numbers have been calculated for the organic phase, the continuous phase in most of the investigated flowsheet, rather than for the mixture (as required by the equation developed by 11]). The viscosity does not affect the $k_{L} a$, due to the same exponent for $C a$ and Re. The different density of the organic and the aqueous phases has a negligible effect on $k_{L} a$, considering the very low exponents in Eq. 17. The change in the density, from organic to aqueous phase, leads to a $2 \%$ reduction in $k_{L} a$. However the density of the mixture is an average value between the aqueous 
and organic ones. Therefore the resulting difference in $k_{L} a$ is expected to be between 0 and $2 \%$.

\section{Results and discussions}

The best flowsheet identified by the superstructure optimisation is shown in Figure 4. Compared with the current process for SNF reprocessing, the PUREX process, this design improves the economics and the safety of the process. The results, in terms of separation and recovery of the metals, are shown in Table 3

All flow rates are reported in Table 4, whereas the outlet concentrations of all components, from each step, are shown in Tables 56. Approximately 85\% of the overall aqueous stream leaving step 2 is recycled to step 1 and $15 \%$ is fed to step 3. In step 4 no additional nitric acid streams are used between stages, to minimise volumes and cost.

The optimal design of each step is shown in Tables 7,8 . The choice of the material of the extractor channels and manifolds may significantly affect the the cost and the design.

The aspects of main interest of the flowsheet, as well as the effect of upper bound of diameter, parameters, constraints and initialisation on the results are further discussed below. 


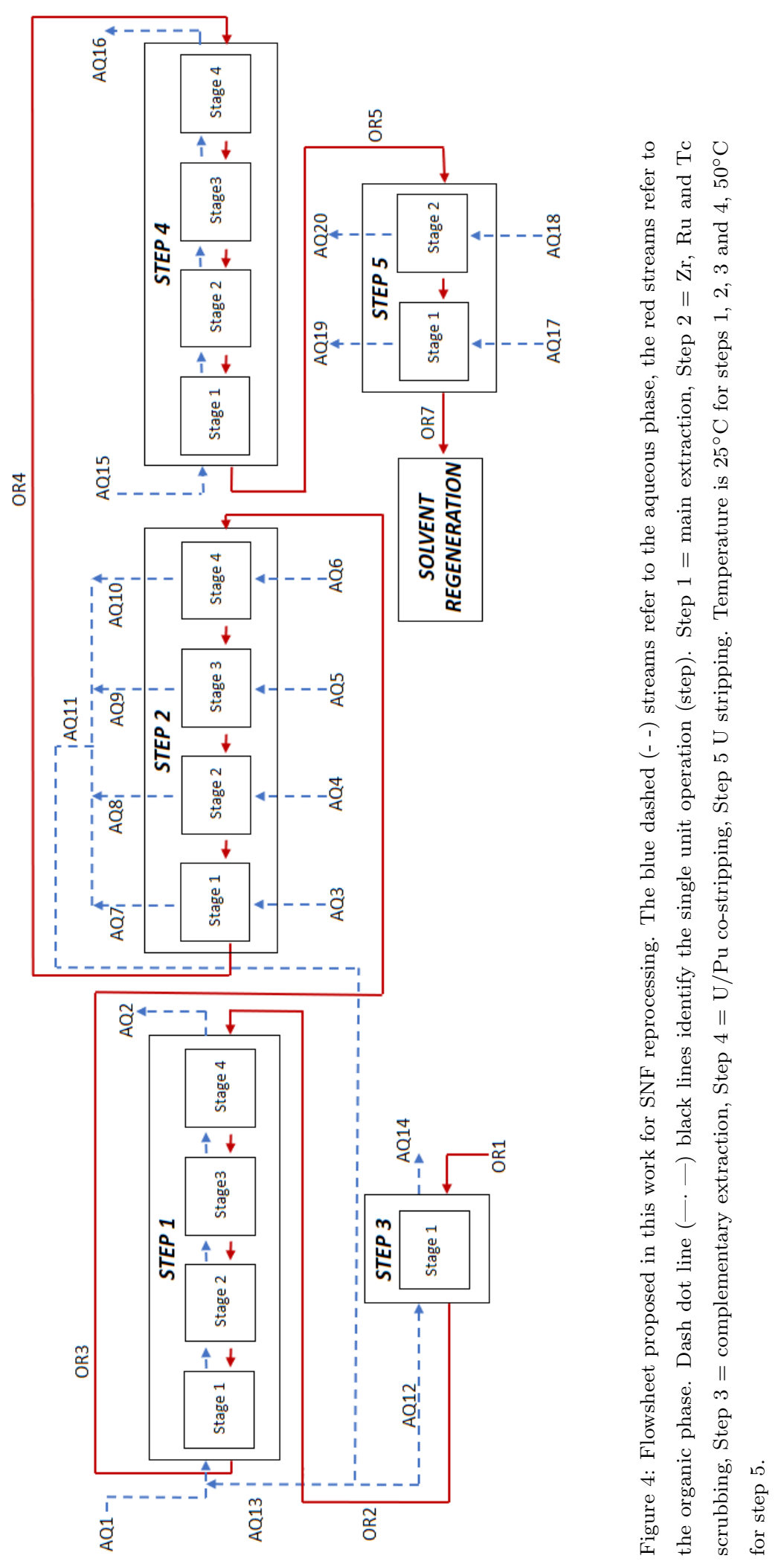




\subsection{Optimal reductant and nitrite scavenger}

For the small-scale contactors, U(IV) is a better reductant than HAN. HAN has slow reaction rates and $\mathrm{Pu}$ does not have sufficient time to back extract in the short residence time of the small channels. Using HAN, no feasible solutions

reduced. The short residence time, an advantage of the small-scale contactors, requires the use of a strong reductant. In the nuclear industry, HAN is used in the $\mathrm{Pu}$ purification section to avoid re-addition of $\mathrm{U}$ in the system. In this flowsheet, however, no pure $\mathrm{Pu}$ is produced but a mixture with $\mathrm{U}$.

370 in the presence of $\mathrm{HNO}_{2}$ (see Eq. 16), which reduces $\mathrm{Pu}$ stripping. Hence, no $\mathrm{N}_{2} \mathrm{H}_{4} \cdot \mathrm{HNO}_{3}$ as nitrite scavenger needs to be used in stream AQ15 (see Figure 4).

\subsection{Optimal TBP concentration}

The optimal TBP fraction used is $32.4 \%(\mathrm{v} / \mathrm{v})$, slightly above the typical value $(30 \%)$. It is reasonable that the TBP fraction is still relatively low, since this flowsheet involves more back extraction steps than extraction steps, hence high TBP concentration would increase the cost of all back extraction steps (the majority) and the overall annualised cost.

380

By increasing the TBP fraction, an increase of the overall cost would be due to step 5, which includes the most expensive channels (made of stainless steel). In step 5 those channels are employed to disperse the organic phase as plugs, in the range of flow ratios investigated, and reduce the number of channels required: the aqueous flow rate is the largest one (back extraction operation) and,

hence, dispersing the organic phase leads to smaller plugs and larger interfacial area, improving mass transfer and reducing the flow rates needed. With flowsheets involving more extraction steps or more cost effective materials for the U stripping, a higher TBP fraction may be beneficial. 


\subsection{Optimal design of cross-flow configurations}

390

total annualised cost has also been reduced by approximately $20 \%$. 
A small reduction of the $k_{L} a$ has been observed as the diameter increases. However, the $k_{L} a$ values are still higher than the ones shown by the authors for conventional technologies 29. To balance the lower mass transfer coefficients, with the larger channels, the superficial velocity becomes lower to allow higher residence times and improve mass transport. The recycle ratio $\chi$ has decreased from $93 \%$ to $85 \%$ when the diameter increased from $2 \mathrm{~mm}$ to $2.5 \mathrm{~mm}$.

The separation achieved by the process remains almost unchanged, the only difference is the increase of $\mathrm{DF}$ for $\mathrm{Np}$ from the case with $D=2.5 \mathrm{~mm}(\mathrm{DF}=9.63)$ to the case with $D=2 \mathrm{~mm}(\mathrm{DF}=11.39)$. This change may be related to the slightly longer residence time used in the case of larger diameter channels. With the longer residence time available, a higher amount of $\mathrm{Np}(\mathrm{V})$ can convert to $\mathrm{Np}(\mathrm{VI})$, which is extractable by TBP.

${ }_{430}$ The linearisation of the mass transfer coefficient correlation, around the upper bound used for the diameter, was reasonable since the optimal diameters have always been the upper bound [32, 37, 29].

\subsection{Impact of input parameters and constraints}

The materials of the channels affect not only the costs of channels and manifolds, but also the hydrodynamics and hence the separation performance, since the continuous phase depends on the wettability of the material used. If, for example, in step 5 (U stripping) a hydrophobic material is used for the small-scale extractors, then the aqueous phase will be dispersed and the organic one will be continuous. Since an aqueous to organic flow ratio greater than 1 is required to back extract uranium, it is beneficial that the organic phase be dispersed, so that the plugs are smaller and the interfacial area larger. Hydrophobic channels, that favour the organic phase as continuous, may also be investigated but they will probably lead to larger, more expensive and/or unpractical manifolds, because higher aqueous phase flow rates would be used to balance the lower interfacial area. Hence, a reasonable choice may be the use of hydrophobic materials for the first 4 steps and a hydrophilic one for step 5 . 
In the optimisation problem, polytetrafluoroethylene (PTFE) was assumed to be the material of construction of all manifolds and all hydrophobic small channels, whilst stainless steel was assumed to be the material of construction of all hydrophilic small channels. However, even though PTFE was used in the past in pulsed columns in the highly active section of the PUREX process [38, 39, 40, nowadays its use with high radiation levels for protracted periods is not recommended [20]. This can be the case of step 1, in particular for the small channels and the manifold for distribution and collection of the aqueous solution. The radiation level depends on the concentration of fissile material in the feed and, here, the feed is significantly diluted with the aqueous stream leaving step 2 and recycled to step 1 (flow rate AQ13, refer to Figure 2). The study of how this dilution affects the radioactivity of the solution goes beyond the scope of this work. Furthermore, limited information is available on the state-of-the-art materials of construction used in spent nuclear fuel reprocessing and their costs. On the contrary, PTFE may be a suitable material for the rest of the process. If a more expensive hydrophobic material was used in step 1 , the total cost of the plant would increase but the impact on the process design would be limited: as the number of stages in step 1 and their volumes are already low, a significant minimisation would not satisfy minimum requirements such as plutonium recovery. What mainly affects the process design is the wettability of the material used for the small channels (i.e. hydrophobic or hydrophilic).

The inequality constraints used for the decontamination factors in the separation process, in particular for Tc (more difficult than $\mathrm{Zr}$ and Ru to separate), affect the aqueous phase flow rates, especially in the first 3 steps. No minimim DF for Np has been used. The Np separation achieved is already better than the typical Np separation achieved with conventional technologies in the current commercial plants. All these constraints are illustrated in Table 1. In general, the higher the minimum DF required, the larger are the aqueous phase flow rates needed, which leads to bigger and more expensive equipment. The increase in flow rates can be accommodated by adding a few elements in the second and third levels of the manifolds, together with a slight increase of the 
manifolds lengths and widths.

The constraint to guarantee nuclear subcriticality does not pose a problem, 
Table 3: Separation performance of the flowsheet proposed.

\begin{tabular}{|c|c|c|}
\hline & Value & Comment \\
\hline$R e c_{\mathrm{U}}^{\text {Steps 1-3 }}$ & $99.21 \%$ & $\begin{array}{l}\text { U recovery in codecontamination } \\
\text { section (steps 1-3), larger than } \\
\text { typical value. }\end{array}$ \\
\hline $\operatorname{Rec}_{\mathrm{Pu}}^{\text {Steps 1-3 }}$ & $99.00 \%$ & $\begin{array}{l}\mathrm{Pu} \text { recovery codecontamination } \\
\text { section (steps 1-3), minimum re- } \\
\text { quirement. }\end{array}$ \\
\hline $\mathrm{DF}_{\mathrm{Zr}}$ & $1 \times 10^{4}$ & $\begin{array}{l}\text { Typical value in codecontamina- } \\
\text { tion section (steps 1-3), mini- } \\
\text { mum requirement. }\end{array}$ \\
\hline $\mathrm{DF}_{\mathrm{Ru}}$ & $4.32 \times 10^{6}$ & $\begin{array}{l}\text { Larger than typical value in } \\
\text { codecontamination } \\
\text { (steps 1-3). }\end{array}$ \\
\hline $\mathrm{DF}_{\mathrm{Tc}}$ & 50.00 & $\begin{array}{l}\text { Larger than typical value in } \\
\text { codecontamination } \\
\text { (steps 1-3). }\end{array}$ \\
\hline $\mathrm{DF}_{\mathrm{Np}}$ & 9.63 & $\begin{array}{l}\text { Larger than typical value in } \\
\text { codecontamination } \\
\text { (steps 1-3). }\end{array}$ \\
\hline $\begin{array}{l}\text { Mixed } \mathrm{U} / \mathrm{Pu} \text { product } \\
\text { purity }\end{array}$ & $99.95 \%$ & $\begin{array}{l}\text { Purity of MOX fuel (stream } \\
\text { AQ16), molar basis. }\end{array}$ \\
\hline U product purity & $99.98 \%$ & $\begin{array}{l}\text { Purity of } \mathrm{U} \text { product (mixing } \\
\text { streams AQ19 and AQ20), molar } \\
\text { basis. }\end{array}$ \\
\hline
\end{tabular}


Table 4: Optimal flow rates and concentrations of nitric acid and additional compounds, i.e. $\mathrm{HNO}_{3}, \mathrm{U}(\mathrm{IV})$ and hydrazine nitrate $\mathrm{N}_{2} \mathrm{H}_{4} \cdot \mathrm{HNO}_{3}$, of the incoming streams. Flow rates are assumed constant within all unit operations, for example AQ2=AQ1+AQ13, AQ3=AQ7, $\mathrm{AQ11}=\mathrm{AQ7}+\mathrm{AQ} 8+\mathrm{AQ9}+\mathrm{AQ} 10$ etc.

\begin{tabular}{lrrrr}
\hline Stream & $\begin{array}{r}{[\mathrm{H} \text { low rate }} \\
{\left[\mathrm{L} \mathrm{h}^{-1}\right]}\end{array}$ & $\begin{array}{r}{\left[\mathrm{HNO}_{3}\right]} \\
{\left[\mathrm{mol} \mathrm{L}^{-1}\right]}\end{array}$ & $\begin{array}{r}{\left[\mathrm{N}_{2} \mathrm{H}_{4} \cdot \mathrm{HNO}_{3}\right]} \\
{\left[\mathrm{mol} \mathrm{L}^{-1}\right]}\end{array}$ \\
\hline AQ1 & $223.65^{1}$ & 2.50 & - & - \\
AQ3 & 175.26 & 4.40 & - & - \\
AQ4 & 175.14 & 4.46 & - & - \\
AQ5 & 181.7 & 4.45 & - & - \\
AQ6 & 168.08 & 4.37 & - & - \\
AQ12 & 107.85 & 4.32 & 0 & 0 \\
AQ13 & 625.10 & 4.42 & 0 & 0 \\
AQ15 & 137.89 & 0.36 & $2.40 \times 10^{-2}$ & 0 \\
AQ17 & 1933.91 & 0.01 & - & - \\
AQ18 & 3063.92 & 0.01 & - & - \\
OR1 & 634.39 & - & - & - \\
\hline
\end{tabular}

\footnotetext{
${ }^{1}$ fixed by the given throughput for the case study
} 
Table 5: Outlet aqueous concentration of components for each step. All concentrations are expressed in $\mathrm{mol} \mathrm{m}^{-3}$.

\begin{tabular}{lrrrrr}
\hline Component & Step 1 & Step 2 & Step 3 & Step 4 & Step 5 \\
\hline $\mathrm{U}(\mathrm{VI})$ & 1.91 & 60.04 & 2.76 & 108.89 & 43.35 \\
$\mathrm{Pu}(\mathrm{IV})$ & $2.68 \times 10^{-2}$ & 0.76 & $3.87 \times 10^{-2}$ & 0.92 & $4.20 \times 10^{-4}$ \\
$\mathrm{HNO}_{3}$ & 3948.72 & 4319.53 & 1898.46 & 1871.61 & 14.56 \\
$\mathrm{HNO}_{2}$ & 0.60 & 2.34 & 0.11 & 0.50 & $6.72 \times 10^{-2}$ \\
$\mathrm{Zr}$ & 3.55 & 0.16 & $4.94 \times 10^{-2}$ & $2.03 \times 10^{-3}$ & 0 \\
$\mathrm{Ru}$ & 2.08 & $1.02 \times 10^{-2}$ & $6.13 \times 10^{-3}$ & 0 & 0 \\
$\mathrm{Tc}$ & 0.72 & 0.34 & 0.18 & $4.28 \times 10^{-2}$ & $1.28 \times 10^{-3}$ \\
$\mathrm{~Np}(\mathrm{IV})$ & 0 & 0 & 0 & 0 & 0 \\
$\mathrm{~Np}(\mathrm{~V})$ & 0.15 & $1.57 \times 10^{-3}$ & $1.49 \times 10^{-3}$ & $1.23 \times 10^{-4}$ & $4.10 \times 10^{-4}$ \\
$\mathrm{~Np}(\mathrm{VI})$ & $2.38 \times 10^{-3}$ & $7.63 \times 10^{-3}$ & $4.20 \times 10^{-4}$ & $1.37 \times 10^{-2}$ & $2.13 \times 10^{-3}$ \\
$\mathrm{U}(\mathrm{IV})$ & 0 & 0 & 0 & 9.19 & 0.27 \\
$\mathrm{Pu}(\mathrm{III})$ & 0 & 0 & 0 & 10.92 & $4.71 \times 10^{-3}$ \\
$\mathrm{~N} 2 \mathrm{H} 4 \cdot \mathrm{HNO}_{3}$ & 0 & 0 & 0 & 0 & 0 \\
$\mathrm{TBP}$ & 0 & 0 & 0 & 0 & 0 \\
\hline
\end{tabular}


Table 6: Outlet organic concentration of components for each step. All concentrations are expressed in $\mathrm{mol} \mathrm{m}^{-3}$.

\begin{tabular}{lrrrrr}
\hline Component & Step 1 & Step 2 & Step 3 & Step 4 & Step 5 \\
\hline $\mathrm{U}(\mathrm{VI})$ & 433.62 & 367.39 & 9.74 & 344.96 & 3.46 \\
$\mathrm{Pu}(\mathrm{IV})$ & 4.90 & 4.07 & 0.12 & $3.34 \times 10^{-3}$ & $2.78 \times 10^{-5}$ \\
$\mathrm{HNO}_{3} \cdot \mathrm{TBP}$ & 234.00 & 338.76 & 260.52 & 25.39 & 0.27 \\
$\mathrm{HNO}_{3} \cdot 2 \mathrm{TBP}$ & 12.83 & 20.56 & 151.06 & 11.02 & 0.22 \\
$\mathrm{HNO}_{2}$ & 5.22 & 2.64 & 0.38 & 2.53 & 2.00 \\
$\mathrm{Zr}$ & 0.17 & $4.60 \times 10^{-4}$ & $1.83 \times 10^{-2}$ & $1.76 \times 10^{-5}$ & 0 \\
$\mathrm{Ru}$ & $1.12 \times 10^{-3}$ & $6.20 \times 10^{-7}$ & $6.90 \times 10^{-4}$ & 0 & 0 \\
$\mathrm{Tc}$ & 0.39 & $1.95 \times 10^{-2}$ & $2.66 \times 10^{-2}$ & $1.02 \times 10^{-3}$ & $1.50 \times 10^{-4}$ \\
$\mathrm{~Np}(\mathrm{IV})$ & 0 & 0 & 0 & 0 & 0 \\
$\mathrm{~Np}(\mathrm{~V})$ & $1.70 \times 10^{-3}$ & $2.43 \times 10^{-7}$ & $1.44 \times 10^{-5}$ & $2.05 \times 10^{-6}$ & $8.08 \times 10^{-7}$ \\
$\mathrm{~Np}(\mathrm{VI})$ & $3.19 \times 10^{-2}$ & $2.34 \times 10^{-2}$ & $1.22 \times 10^{-3}$ & $2.02 \times 10^{-2}$ & $1.50 \times 10^{-4}$ \\
$\mathrm{U}(\mathrm{IV})$ & 0 & 0 & 0 & 2.13 & $1.15 \times 10^{-3}$ \\
$\mathrm{Pu}(\mathrm{III})$ & 0 & 0 & 0 & $3.73 \times 10^{-2}$ & $1.90 \times 10^{-4}$ \\
$\mathrm{~N} 2 \mathrm{H} 4 \cdot \mathrm{HNO}_{3}$ & 0 & 0 & 0 & 0 & 0 \\
$\mathrm{TBP}$ & 34.80 & 55.38 & 600.32 & 432.41 & 1171.88 \\
\hline
\end{tabular}


Table 7: Optimal design of steps 1 (main extraction step), 2 (scrubbing), 3 (complementary extraction) and 4 (co-stripping). The number of elements in each level of the manifold is the same. Lengths, diameters and widths are expressed in $\mathrm{cm}$.

\begin{tabular}{|c|c|c|c|c|c|}
\hline & Phase & Step 1 & Step 2 & Step 3 & Step 4 \\
\hline No. of stages & - & 4 & 4 & 1 & 4 \\
\hline \multicolumn{6}{|l|}{$1^{\text {st }}$ level manifold } \\
\hline No. of elements & - & 70 & 70 & 70 & 70 \\
\hline Length & Both & 10.0 & 10.0 & 10.0 & 10.0 \\
\hline Diameter & Both & $2.5 \times 10^{-1}$ & $2.5 \times 10^{-1}$ & $2.5 \times 10^{-1}$ & $2.5 \times 10^{-1}$ \\
\hline \multicolumn{6}{|l|}{$2^{\text {nd }}$ level manifold: } \\
\hline No. of elements & - & 14 & 7 & 7 & 6 \\
\hline Length & Aq. & 51.8 & 51.8 & 51.8 & 51.8 \\
\hline Width & Aq. & 1.0 & 1.0 & 1.0 & 0.9 \\
\hline Length & Org. & 51.8 & 51.8 & 51.8 & 51.8 \\
\hline Width & Org. & 1.2 & 1.1 & 1.1 & 1.1 \\
\hline \multicolumn{6}{|l|}{$3^{\text {rd }}$ level manifold: } \\
\hline No. of elements & - & 14 & 6 & 7 & 5 \\
\hline Length & Aq. & 40.1 & 17.9 & 18.4 & 14.2 \\
\hline Width & Aq. & 2.3 & 1.5 & 1.4 & 1.3 \\
\hline Length & Org. & 45.8 & 20.4 & 21.0 & 16.3 \\
\hline Width & Org. & 2.6 & 2.3 & 2.5 & 2.1 \\
\hline \multicolumn{6}{|l|}{$4^{\text {th }}$ level manifold: } \\
\hline No. of elements & - & 1 & 1 & 1 & 1 \\
\hline Length & Aq. & 91.2 & 22.2 & 25.1 & 15.3 \\
\hline Width & Aq. & 2.4 & 1.5 & 1.4 & 1.3 \\
\hline Length & Org. & 102.0 & 35.2 & 44.5 & 26.6 \\
\hline Width & Org. & 2.6 & 2.3 & 2.5 & 2.1 \\
\hline
\end{tabular}


Table 8: Optimal design of step 5, U stripping. Number of stages: 2. Length and width are expressed in $\mathrm{cm}$.

\begin{tabular}{|c|c|c|c|}
\hline & Phase & Stage 1 & Stage 2 \\
\hline \multicolumn{4}{|l|}{$1^{\text {st }}$ level manifold: } \\
\hline No. of elements & - & 70 & 70 \\
\hline Length & Both & 10.0 & 10.0 \\
\hline Diameter & Both & $2.5 \times 10^{-1}$ & $2.5 \times 10^{-1}$ \\
\hline \multicolumn{4}{|l|}{$2^{\text {nd }}$ level manifold: } \\
\hline No. of elements & - & 10 & 12 \\
\hline Length & Aq. & 51.7 & 51.7 \\
\hline Width & Aq. & 1.0 & 1.0 \\
\hline Length & Org. & 51.7 & 51.7 \\
\hline Width & Org. & 1.1 & 1.1 \\
\hline \multicolumn{4}{|l|}{$3^{\text {rd }}$ level manifold: } \\
\hline No. of elements & - & 10 & 11 \\
\hline Length & Aq. & 25.7 & 31.4 \\
\hline Width & Aq. & 2.3 & 2.7 \\
\hline Length & Org. & 29.3 & 35.9 \\
\hline Width & Org. & 1.9 & 1.8 \\
\hline \multicolumn{4}{|l|}{$4^{\text {th }}$ level manifold: } \\
\hline No. of elements & - & 1 & 1 \\
\hline Length & Aq. & 62.6 & 87.9 \\
\hline Width & Aq. & 2.3 & 2.9 \\
\hline Length & Org. & 51.2 & 60.3 \\
\hline Width & Org. & 1.9 & 2.0 \\
\hline
\end{tabular}




\section{Conclusions}

A superstructure model for nuclear fuel reprocessing design has been inves-

500 tigated, to explore alternative flowsheets to the current PUREX process. The application of small-scale extractors, to overcome the disadvantages of the conventional technologies, has been investigated. The system involves 15 species and 12 chemical, mostly redox, reactions. Counter-current and cross-flow configurations have been considered, depending on the unit operation. The resulting model allows to explore alternative flowsheets for SNF reprocessing at a conceptual level, due to the lack of detailed kinetic and cost data. The mass transfer model and the ranges of validity in terms of channel diameters, velocities and flow rate ratios should be further investigated.

The flowsheet proposed has several advantages over the current process for SNF reprocessing. Two products, uranium oxide and a mixed uranium/plutonium oxide (MOX) are achieved, precluding nuclear proliferation risks. Also, this MOX product has a better homogeneity of uranium/plutonium distribution within the oxide, when compared with the current MOX fuel fabrication technique. Less unit operations are involved, reducing capital and operational costs and leading to improvements in safety considerations and equipment footprint.

The results suggest that, using small-scale extractors, the use of U(IV) as reductant is more suitable than HAN, because of the faster kinetics which allow the complete $\mathrm{Pu}$ reduction in the short residence times achieved in the small channels. The cross-flow operation in the scrubbing and stripping stages, although increasing the amount of nitric solution required, allows high decontamination of minor actinides and fission products (equal or higher to the typical industrial requirements). Increasing the diameter of the channels up to $2.5 \mathrm{~mm}$, according to the model, may be beneficial to reduce the overall cost, because of the simpler manifolds, and may still provide high separation and higher volumetric mass transfer coefficients than conventional technologies.

Centrifuges and/or filters are employed to remove fuel cladding debris and any other undissolved particles. However, potential solid sedimentation may 
occur and periodic maintenance works may be needed. Encrustation can occur, as well. This aspect requires further investigation. However, a channel diameter in the order of millimetres will minimise the risk of occlusion.

Future work may include the integration of further fission products in the flowsheet and more specific correlations for mass transfer coefficients. Further flowsheets and different routes, e.g. Pu discharged with high level wastes and pure $\mathrm{U}$ produced, or separation of minor actinides such as Np, may be investigated. Finally, the combination of conventional and small-scale technologies may lead to significantly higher throughput and is worth investigating.

\section{Acknowledgements}

The authors would like to acknowledge the UK Engineering and Physical Sciences Research Council (EPSRC) for funding provided as the PACIFIC project, EP/L018616/1. D. Bascone would also like to thank University College London (UCL) for his PhD studentship.

\section{Nomenclature}

$\begin{array}{lll}\text { Symbols } & \text { Description } & \text { Units } \\ \text { ACapEx } & \text { Annual Capital expenditure } & £ \mathrm{y}^{-1} \\ C & \text { Concentration } & \mathrm{mol} \mathrm{m}^{-3} \\ C a & \text { Capillarity number }\left(\frac{v \mu}{\gamma}\right) & \\ C a p E x & \text { Capital expenditure } & \mathrm{m} \\ D & \text { Diameter } & \\ & \text { Distribution coefficient } & \mathrm{kPa} \\ \Delta P & \text { Pressure drop } & \\ E & \text { Separation Efficiency } & \\ F & \text { TBP volume fraction } & \\ i & \text { annual interest } & \mathrm{m} \\ L & \text { Length } & \\ k_{e f f} & \text { Effective multiplication factor } & \mathrm{s}^{-1} \\ k_{L} a & \text { Volumetric mass transfer coefficient }\end{array}$




$\begin{array}{lll}K & \text { pseudo-equilibrium costant } & \\ N & \text { number of elements in each level of the } & \\ & \text { manifolds } & \mathrm{y} \\ q & \text { payout time } & \\ O p E x & \text { Aqueous to organic flow ratio } & £ \mathrm{y}^{-1} \\ r & \text { Operating expenditure } & \mathrm{m} \\ r & \text { Radius } & \\ R & \text { Hydraulic resistance ratio } & \mathrm{mol} \mathrm{L}^{-1} \mathrm{~s}^{-1} \\ R e & \text { Reaction rate } & \\ R e c & \text { Reynolds number }\left(\frac{\rho v D}{\mu}\right) & \\ T & \text { Recovery } & \mathrm{K}^{2} \\ t & \text { Temperature } & \mathrm{s} \\ T A C & \text { time } & £ \mathrm{y}^{-1} \\ v & \text { Total annaulised cost } & \mathrm{m} \mathrm{s}^{-1}\end{array}$

Greek Symbols

$\alpha \quad$ Ratio between disperse plug length and unit cell

$\gamma \quad$ Interfacial tension $\quad \mathrm{N} \mathrm{m}^{-1}$

$\mu \quad$ Viscosity $\quad$ Pa s

$\eta \quad$ Pump efficiency

$\rho \quad$ Mass density $\quad \mathrm{kg} \mathrm{m}^{-3}$

$\theta \quad$ Contact angle

$\tau \quad$ Temperature dependent function for distribution coefficient calculation

$\varphi \quad$ Phase holdup

$\chi \quad$ Recycle ratio

$\zeta \quad$ Resistant coefficient

Subscripts and superscripts

$a q \quad$ Aqueous phase 


\begin{tabular}{|c|c|}
\hline$e q$ & Equilibrium \\
\hline for & Forward \\
\hline$k$ & Generic phase \\
\hline$i$ & Generic component \\
\hline int & Interfacial \\
\hline $\operatorname{mix}$ & Mixture \\
\hline or & Organic phase \\
\hline out & Outlet \\
\hline$r e v$ & Reverse \\
\hline$U C$ & Unit Cell \\
\hline \multicolumn{2}{|c|}{ Acronysms } \\
\hline COEX & Combined Uranium Plutonium Extraction \\
\hline $\mathrm{DF}$ & Decontamination factor \\
\hline GAMS & General Algebraic Modeling System \\
\hline MINLP & Mixed Integer Nonlinear Programming \\
\hline MOX & Mixed Oxide \\
\hline PTFE & Polytetrafluoroethylene \\
\hline PUREX & Plutonium Uranium Extraction \\
\hline SBB & Simple Branch and Bound \\
\hline SNF & Spent Nuclear Fuel \\
\hline TBP & Tributyl Phosphate \\
\hline
\end{tabular}

\section{Appendices}

\section{A. Calculation of distribution coefficients}

Distribution coefficient of $\mathrm{U}(\mathrm{VI})$ is calculated as suggested by Richardson 545 and Swanson [41]:

$$
D_{\mathrm{U}}=K_{\mathrm{U}}[\mathrm{TBP}]_{o r}^{2}
$$


where $[\mathrm{TBP}]_{\text {or }}$ is the unbounded TBP concentration in the organic phase. The pseudo-equilibrium constant $K_{U}$ is estimated by the following equation :

$$
K_{\mathrm{U}}=\left(3.7\left[\mathrm{NO}_{3}^{-}\right]_{a q}^{1.57}+1.4\left[\mathrm{NO}_{3}^{-}\right]_{a q}^{3.9}+0.011\left[\mathrm{NO}_{3}^{-}\right]_{a q}^{7.3}\right)\left(4 F^{-0.17}-3\right) e^{2500 \tau}
$$

where $\tau$ is the temperature-dependent function as follows:

$$
\tau=\frac{1}{T}-\frac{1}{298}
$$

Distribution coefficient and pseudo-equilibrium constant of $\mathrm{Pu}(\mathrm{IV})$ and $\mathrm{HNO}_{3}$ are considered functions of ionic strength $\left[\mathrm{NO}_{3}^{-}\right]$, temperature and TBP concentration:

$$
\begin{gathered}
D_{\mathrm{Pu}}=K_{\mathrm{Pu}}[\mathrm{TBP}]_{o r}^{2} \\
K_{\mathrm{Pu}}=K_{\mathrm{U}}\left(0.20+0.55 F^{1.25}+0.0074\left[\mathrm{NO}_{3}^{-}\right]_{a q}^{2}\right)\left(4 F^{-0.17}-3\right) e^{-200 \tau} \\
D_{\mathrm{H} 1}=K_{\mathrm{H} 1}[\mathrm{TBP}]_{o r} \\
D_{\mathrm{H} 2}=K_{\mathrm{H} 2}[\mathrm{TBP}]_{o r}^{2} \\
\left.K_{\mathrm{H} 1}=\left(0.135\left[\mathrm{NO}_{3}^{-}\right]_{a q}^{0.85}+0.005[\mathrm{NO}]_{a q}^{-}\right]_{a q}^{3.44}\right)\left(1-0.54 e^{-15 F} e^{340 \tau}\right) \\
K_{\mathrm{H} 2}=K_{\mathrm{H} 1}
\end{gathered}
$$

where the subscripts $\mathrm{H} 1$ and $\mathrm{H} 2$ refer to the two complexes nitric acid can form in the organic phase [41, 42].

Distribution coefficients of $\mathrm{Zr}$ and $\mathrm{Ru}$ have been calculated as described 555 below 43 :

$$
D_{\mathrm{Zr}}=K_{\mathrm{Zr}}[\mathrm{TBP}]_{o r}^{2}
$$




$$
\begin{gathered}
\ln K_{\mathrm{Zr}}=0.2685\left[\mathrm{NO}_{3}^{-}\right]_{a q}^{2}-0.6359\left[\mathrm{NO}_{3}^{-}\right]_{a q}+0.4853 \\
D_{\mathrm{Ru}}=K_{\mathrm{Ru}}[\mathrm{TBP}]_{o r}^{2}
\end{gathered}
$$

$$
\ln K_{\mathrm{Ru}}=-0.0691\left[\mathrm{NO}_{3}^{-}\right]_{a q}^{3} 0.8356\left[\mathrm{NO}_{3}^{-}\right]_{a q}^{2}-2.3672\left[\mathrm{NO}_{3}^{-}\right]_{a q}+0.9165
$$

Distribution coefficient of Tc is calculated as proposed by Asakura et al. 44]:

$$
\begin{gathered}
D_{\mathrm{Tc}}=D_{\mathrm{Tc}, 0}+D_{\mathrm{Tc}, \mathrm{U}}+D_{\mathrm{Tc}, \mathrm{Pu}}+D_{\mathrm{Tc}, \mathrm{Zr}} \\
D_{\mathrm{Tc}, 0}=0.845[\mathrm{TBP}]_{o r}^{1.92 e^{3300 \tau}} \frac{2.324\left[\mathrm{NO}_{3}^{-}\right]_{a q}^{0.848 e^{230 \tau}} e^{8070 \tau} e^{-350 \tau}}{1+0.157\left[\mathrm{NO}_{3}^{-}\right]_{a q}^{4.69 e^{410 \tau}} e^{324 \tau}+1.72\left[\mathrm{NO}_{3}^{-}\right]_{a q}^{1.95 e^{160 \tau}} e^{3150 \tau}} \\
D_{\mathrm{Tc}, \mathrm{U}}=0.331 \frac{\left[\mathrm{UO}_{2}^{2+}\right]_{o r}}{\left[\mathrm{UO}_{2}^{2+}\right]_{o r}+\left[\mathrm{Pu}^{4+}\right]_{o r}}\left\{1+4.87\left[\mathrm{NO}_{3}^{-}\right]_{a q}^{-1.343} e^{980 \tau}\right\} e^{-1060 \tau} \\
D_{\mathrm{Tc}, \mathrm{Pu}}=3.31\left[\mathrm{NO}_{3}^{-}\right]_{a q}^{-0.707} \frac{\left[\mathrm{UO}_{2}^{2+}\right]_{o r}}{\left[\mathrm{UO}_{2}^{2+}\right]_{o r}+\left[\mathrm{Pu}^{4+}\right]_{o r}} e^{-1060 \tau} \\
D_{\mathrm{Tc}, \mathrm{Zr}}=1670[\mathrm{Zr}]_{o r}\left[\mathrm{NO}_{3}^{-}\right]_{a q}^{-0.707} e^{2810 \tau}
\end{gathered}
$$

Distribution coefficient of $\mathrm{Np}(\mathrm{VI})$ is estimated as follows [45, 46]:

$$
D_{\mathrm{Np}(\mathrm{VI})}=0.52768 D_{\mathrm{U}}
$$

Distribution coefficient of $\mathrm{HNO}_{2}$ is calculated as [47]:

$$
D_{\mathrm{HNO}_{2}}=25[\mathrm{TBP}]_{\text {or }}
$$


Distribution coefficient of $\mathrm{U}(\mathrm{IV})$ and $\mathrm{Pu}(\mathrm{III})$ are calculated as suggested by Kumar and Koganti [48, 49]:

$$
\begin{aligned}
D_{\mathrm{Pu}(\mathrm{III})} & =1.138 \times 10^{-2} D_{\mathrm{U}(\mathrm{VI})} \\
D_{\mathrm{U}(\mathrm{IV})} & =\left(0.0541+0.000658\left[\mathrm{NO}_{3}^{-}\right]^{2}\right) D_{\mathrm{U}(\mathrm{VI})}
\end{aligned}
$$

\section{B. Calculation of chemical reactions}

The reaction rates included in this work are shown in Table 10. Reaction 5 . in the organic phase, is assumed to be only a forward reaction from $\mathrm{Np}(\mathrm{V})$ to Np(VI) 50. 
Table 10: Reaction rates included in the problem. Kinetic constants are given at $25^{\circ} \mathrm{C}$. For different temperatures, the values of the kinetic constants below are re-calculated using the activation energy provided by the cited authors.

\begin{tabular}{|c|c|c|c|c|}
\hline Reaction & Reactio & rate $\left[\mathrm{mol} \mathrm{L}^{-1} \mathrm{~s}^{-1}\right]$ & Phase & Ref. \\
\hline 5 & $R_{\text {for }}=$ & $\begin{array}{l}2.884 \times 10^{11} e^{-\frac{9922}{T}}\left[\mathrm{NpO}_{2}^{+}\right]_{a q}\left[\mathrm{HNO}_{2}\right]_{a q}^{0.5} \\
\times\left[\mathrm{H}^{+}\right]_{a q}^{2}\left[\mathrm{NO}_{3}^{-}\right]_{a q}+5.405 \times 10^{12} e^{-\frac{10003}{T}} \\
\times\left[\mathrm{NpO}_{2}^{+}\right]_{a q}\left[\mathrm{HNO}_{2}\right]_{a q}\left[\mathrm{H}^{+}\right]_{a q}\end{array}$ & aq. & 51 \\
\hline 5 & $R_{\text {rev }}=$ & $\begin{array}{l}13.856 \times 10^{10} e^{-\frac{7505}{T}}\left[\mathrm{NpO}_{2}^{2+}\right]_{a q}\left[\mathrm{HNO}_{2}\right]_{a q} \\
\times\left[\mathrm{H}^{+}\right]_{a q}^{-1}+4.994 \times 10^{12} e^{-\frac{7806}{T}}\left[\mathrm{NpO}_{2}^{2+}\right]_{a q} \\
\times\left[\mathrm{HNO}_{2}\right]_{a q}^{1.5}\left[\mathrm{H}^{+}\right]_{a q}^{-0.5}\left[\mathrm{NO}_{3}^{-}\right]_{a q}^{-0.5}\end{array}$ & aq. & 51 \\
\hline 5 & $R_{f o r}=$ & $\begin{array}{l}1.952 \times 10^{11} e^{-\frac{9008}{T}}[\mathrm{~Np}(\mathrm{~V})]_{o r}\left[\mathrm{HNO}_{2}\right]_{a q}^{0.5}\left[\mathrm{H}^{+}\right]_{a q}^{0.5} \\
\times\left[\mathrm{H}_{2} \mathrm{O}\right]_{o r}^{-0.2}\end{array}$ & org. & 50 \\
\hline 6 & $R_{\text {for }}=$ & $1.22 \times 10^{-2} \frac{\left[\mathrm{Pu}^{4+}\right]^{2}}{\left[\mathrm{Pu}^{3+}\right]^{2}} \frac{\left[\mathrm{NH}_{3} \mathrm{OH}^{+}\right]^{2}}{\left[\mathrm{H}^{+}\right]^{4}\left(\left[\mathrm{NO}_{3}^{-}+0.33\right]^{2}\right)}$ & aq. & 52 \\
\hline 7 & $R_{\text {for }}=$ & $5.33\left[\mathrm{H}^{+}\right]\left[\mathrm{NH}_{3} \mathrm{OH}^{+}\right]\left[\mathrm{HNO}_{2}\right]$ & aq. & 40 \\
\hline 8 & $R_{\text {for }}=$ & $1.54\left[\mathrm{NpO}_{2}^{2+}\right]\left[\mathrm{NH}_{3} \mathrm{OH}^{+}\right]\left[\mathrm{H}^{+}\right]^{-1}$ & aq. & 52 \\
\hline 9 & $R_{\text {for }}=$ & $8.33 \times 10 \frac{\left[\mathrm{Pu}^{4+}\right]^{2}\left[\mathrm{U}^{4+}\right]^{2}}{\left[\mathrm{H}^{+}\right]+0.05^{2}}$ & aq. & 52 \\
\hline 9 & $R_{\text {for }}=$ & $8.33 \times 10^{-2} \frac{\left[\mathrm{Pu}^{4+}\right]^{2}\left[\mathrm{U}^{4+}\right]^{2}}{\left[\mathrm{H}^{+}\right]+0.05^{2}}$ & org. & 52 \\
\hline 10 & $R_{f o r}=$ & $1.17 \times 10^{-1}\left[2 \mathrm{NpO}_{2}^{2+}\right]\left[\mathrm{U}^{4+}\right]$ & aq. & 52 \\
\hline 12 & $R_{\text {for }}=$ & $\begin{array}{l}3.75 \times 10^{-2}\left[\mathrm{NpO}_{2}^{+}\right]\left[\mathrm{U}^{4+}\right]\left(1.6\left[\mathrm{H}^{+}\right]^{-2}\right. \\
\left.+1.42\left[\mathrm{H}^{+}\right]\right)\end{array}$ & aq. & 52 \\
\hline 11 & $R_{\text {for }}=$ & $1.38 \times 10^{-1}\left[\mathrm{NpO}_{2}^{2+}\right]\left[\mathrm{N}_{2} \mathrm{H}_{5}^{+}\right]\left[\mathrm{H}^{+}\right]^{-1.3}$ & aq. & 52 \\
\hline 13 & $R_{\text {for }}=$ & $6.33 \times 10^{-4} \frac{\left[\mathrm{Pu}^{4+}\right]^{2}\left[\mathrm{~N}_{2} \mathrm{H}_{5}^{+}\right]}{\left[\mathrm{H}^{+}\right]+0.35}$ & aq. & 52 \\
\hline 14 & $R_{f o r}=$ & $6.17\left[\mathrm{H}^{+}\right]\left[\mathrm{N}_{2} \mathrm{H}_{5}^{+}\right]\left[\mathrm{HNO}_{2}\right]$ & aq. & 40 \\
\hline 15 & $R_{\text {for }}=$ & $5.33\left[\mathrm{U}^{4+}\right]\left[\mathrm{H}^{+}\right]^{2.7}\left[\mathrm{HNO}_{2}\right]^{0.38}$ & aq. & 40 \\
\hline 15 & $R_{\text {for }}=$ & $2.67 \times 10^{-4}\left[\mathrm{U}^{4+}\right]\left[\mathrm{HNO}_{2}\right]^{0.49}$ & org. & 40 \\
\hline 16 & $R_{\text {for }}=$ & $1.04 \times 10^{-1}\left[\mathrm{Pu}^{3+}\right]\left[\mathrm{HNO}_{2}\right]^{0.5}\left[\mathrm{H}^{+}\right]^{0.5}\left[\mathrm{NO}_{3}^{-}\right]^{0.4}$ & aq. & 52 \\
\hline
\end{tabular}




\section{Calculation of pressure drops}

565

$$
\Delta P_{\text {tot }}=\Delta P_{f r, a q}+\Delta P_{f r, o r g}+\Delta P_{i n t}
$$

where $\Delta P_{f r}$ and $\Delta P_{i n t}$ are estimated as suggested by Kashid and Agar [9]:

$$
\begin{gathered}
\Delta P_{f r, a q}=\frac{8 \mu_{a q} v_{m i x} \alpha L_{U C}}{r^{2}} \\
\Delta P_{f r, o r g}=\frac{8 \mu_{o r} v_{m i x}(1-\alpha) L_{U C}}{r^{2}} \\
\Delta P_{\text {int }}=\frac{2 \gamma}{r} \cos \theta
\end{gathered}
$$

The values of $L_{U C}$ and $\alpha$ have been considered constants in this work and equal to, respectively, approximately $4 \mathrm{~mm}$ and 0.7 . The contact angle $\theta$ used is $70^{\circ}$. These values do not affect significantly the optimal design, as the largest contribute to the overall pressure drop is given by the singularity losses.

Singularity losses considered are due to mixing of the two phases (in the mixing junction, when the two phases join the small extractor) and to a series of local pressure drops in the manifolds, due to: contraction, turning, splitting, combining and increase in the cross-sectional area. Each singularity loss is 575

$$
\Delta P_{\text {singularity }}=\zeta \frac{\rho v^{2}}{2}
$$

where the parameter $\zeta$ is the resistance coefficient for each type of singularity loss [32, 53. The singularity losses in the manifolds are expected to be negligible if laminar flow is achieved, whilst the one in the mixing junction represents the largest pressure drop. 
The cost of each channel is estimated as follows:

$$
\text { Cost }_{\text {channel }}=\left(K_{1} D+K_{2}\right) L
$$

where $K_{1}$ and $K_{2}$ are, respectively, $£ 261.8 \mathrm{~m}^{-2}$ and $£ 0.5 \mathrm{~m}^{-1}$ if the channels are made of PTFE, whilts they are $£ 100879.0 \mathrm{~m}^{-2}$ and $£ 4.3 \mathrm{~m}^{-1}$ if they are of stainless steel 32 .

Each mixing junction is assumed to cost, as first approximation, £31.8. The cost of each manifold is, hence, calculated as the sum of the cost of all channels in levels 1, 2, 3 and 4 (using Eq. 46) and the cost of all mixing junctions required. The overall capital cost CapEx is therefore given by the cost of all manifolds (including mixing junctions and channels) required. The annual capital expenditure $A C a p E x$ is calculated as:

$$
A C a p E x=\operatorname{Cap} E x \frac{i(1+i)^{n}}{(1+i)^{n}-1}
$$

where $i$ is the annual interest, assumed $5 \%$, and $n$, which is 5 years, is the payout time [54.

The operating expenditure are related to the pumping costs, estimated as:

$$
O p E x=\frac{\Delta P_{t o t} \dot{V}}{\eta} \text { Cost }_{\text {energy }} s f
$$

where $\eta$ is 0.8, Cost $_{\text {energy }}$ is $£ 0.1$ per $\mathrm{kWh}, s f$ the scaling factor to express the operating expenditure in $£ \mathrm{y}^{-1}$.

\section{E. Calculation of mass balance}

The mass balance within the small extractors is calculated by Eq. 4 .

The mass balance between the different unit operations is calculated according to the flowsheet depicted in Figure 2.

\section{F. Input parameters}

In Table 11. all input parameters used in the optimisation problem are shown. 
Table 11: Feed concentration, temperatures, throughput, materials of the small-channels and flow pattern designs assumed in this work.

\begin{tabular}{lrr}
\hline Parameter & Component/Step & Value \\
\hline Feed concentration & $\mathrm{U}(\mathrm{VI})$ & 1050.42 \\
{$\left[\mathrm{Mol} \mathrm{m}^{-3}\right]$} & $\mathrm{Pu}(\mathrm{IV})$ & 11.65 \\
& $\mathrm{Ru}$ & 7.59 \\
& $\mathrm{Zr}$ & 12.99 \\
& $\mathrm{Tc}$ & 2.77 \\
& $\mathrm{~Np}(\mathrm{~V})$ & 0.64 \\
& $\mathrm{HNO} \mathrm{O}_{2}$ & 1.00 \\
\hline Temperature $\left[{ }^{\circ} \mathrm{C}\right]$ & Steps $1,2,3,4$ & 25 \\
& $\mathrm{Step} 5$ & 50 \\
\hline Throughput $\left[\mathrm{MTHM} \mathrm{\textrm {y } ^ { - 1 } ]}\right.$ & - & 500 \\
\hline Channel material & Steps $1,2,3,4$ & Hydrophobic \\
& Step 5 & Hydrophilic \\
\hline Flow pattern design & Steps $1,3,4$ & Counter-current \\
& Step 2, & Cross-flow \\
\hline
\end{tabular}




\section{References}

[1] IAEA, Spent fuel reprocessing options, in: IAEA-TECDOC-1587, 2008.

[2] R. T. Jubin, Spent fuel reprocessing, Tech. rep., Oak Ridge National Laboratory (2009).

[3] L. Borges Silverio, W. d. Q. Lamas, An analysis of development and research on spent nuclear fuel reprocessing, Energy Policy 39 (1) (2011) 281289.

[4] R. S. Herbst, P. Baron, M. Nilsson, Standard and advanced separation: PUREX processes for nuclear fuel reprocessing, in: K. L. Nash, G. J. Lumetta (Eds.), Advanced Separation Techniques for Nuclear Fuel Reprocessing and Radioactive Waste Treatment, Woodhead Publishing Series in Energy, Woodhead Publishing, 2011, pp. 141-175.

[5] G. J. Lumetta, J. R. Allred, S. A. Bryan, G. B. Hall, T. G. Levitskaia, A. M. Lines, S. I. Sinkov, Simulant testing of a co-decontamination (CoDCon) flowsheet for a product with a controlled uranium-to-plutonium ratio, Separation Science and Technology 0 (0) (2019) 1-8.

[6] D. Tsaoulidis, V. Dore, P. Angeli, N. V. Plechkova, K. R. Seddon, Dioxouranium(VI) extraction in microchannels using ionic liquids, Chemical Engineering Journal 227 (2013) 151-157.

[7] D. Tsaoulidis, V. Dore, P. Angeli, N. V. Plechkova, K. R. Seddon, Extraction of dioxouranium(VI) in small channels using ionic liquids, Chemical Engineering Research and Design 91 (4) (2013) 681-687.

[8] D. Tsaoulidis, P. Angeli, Effect of channel size on mass transfer during liquid-liquid plug flow in small scale extractors, Chemical Engineering Journal 262 (2015) 785-793. 
[9] M. N. Kashid, D. W. Agar, Hydrodynamics of liquid-liquid slug flow capillary microreactor: flow regimes, slug size and pressure drop, Chemical Engineering Journal Vol. 131, 1-13.

[10] M. N. Kashid, Y. M. Harshe, D. W. Agar, Liquid-liquid slug flow in a capillary: an alternative to suspended drop or film contactors, Industrial \& Engineering Chemistry Research 46 (25) (2007) 8420-8430.

[11] M. N. Kashid, A. Gupta, A. Renken, L. Kiwi-Minsker, Numbering-up and mass transfer studies of liquid-liquid two-phase microstructured reactors, Chemical Engineering Journal 158 (2) (2010) 233-240.

[12] D. Tsaoulidis, P. Angeli, Effect of channel size on liquid-liquid plug flow in small channels, AIChE Journal 62 (1) (2016) 315-324.

[13] S. Becht, R. Franke, A. Geißelmann, H. Hahn, An industrial view of process intensification, Chemical Engineering and Processing: Process Intensification 48 (1) (2009) 329-332.

[14] C. Ramshaw, Higee distillation-an example of process intensification, Chemical Engineering 389 (1983) 13-14.

[15] W. Cross, C. Ramshaw, Process intensification: laminar flow heat transfer, Chemical Engineering Research and Design 64 (1986) 293-301.

[16] C. Tsouris, J. V. Porcelli, Process intensification - has its time finally come?, Chemical Engineering Progress; New York 99 (10) (2003) 50.

[17] A. I. Stankiewicz, J. A. Moulijn, Process intensification: Transforming chemical engineering, Chemical Engineering Progress; New York 96 (1) (2000) 22 .

[18] T. Van Gerven, A. Stankiewicz, Structure, energy, synergy, time - the fundamentals of process intensification, Industrial \& Engineering Chemistry: 48 (5) (2009) 2465-2474. 
[19] Y. Tian, S. E. Demirel, M. M. F. Hasan, E. N. Pistikopoulos, An overview of process systems engineering approaches for process intensification: State of the art, Chemical Engineering and Processing - Process Intensification 133 (2018) 160-210.

[20] S. Arm, C. Phillips, Chemical engineering for advanced aqueous radioactive materials separations, in: K. L. Nash, G. J. Lumetta (Eds.), Advanced Separation Techniques for Nuclear Fuel Reprocessing and Radioactive Waste Treatment, Woodhead Publishing Series in Energy, Woodhead Publishing, 2011, pp. 58-94.

[21] J. D. Law, T. A. Todd, Liquid-liquid extraction equipment, Tech. Rep. INL/CON-08-15151, Idaho National Laboratory, United States (2008).

[22] I. Grossmann, C. M. U. E. D. R. Center, MINLP optimization strategies and algorithms for process synthesis, Department of Chemical Engineering.

[23] M. Martín, I. E. Grossmann, Energy optimization of bioethanol production via hydrolysis of switchgrass, AIChE Journal 58 (5) (2012) 1538-1549.

[24] M. Martín, I. E. Grossmann, ASI: Toward the optimal integrated production of biodiesel with internal recycling of methanol produced from glycerol, Environmental Progress \& Sustainable Energy 32 (4) (2013) 891-901.

[25] M. Martín, I. E. Grossmann, Optimal simultaneous production of i-butene and ethanol from switchgrass, Biomass and Bioenergy 61 (2014) 93-103.

[26] X. Yang, H.-G. Dong, I. E. Grossmann, A framework for synthesizing the optimal separation process of azeotropic mixtures, AIChE Journal 58 (5) (2012) 1487-1502.

[27] L. Yang, R. Salcedo-Diaz, I. E. Grossmann, Water network optimization with wastewater regeneration models, Industrial \& Engineering Chemistry Research 53 (45) (2014) 17680-17695. 
[28] GAMS Development Corporation, General Algebraic Modeling System (GAMS) Release 24.2.1, Washington, DC, USA (2013).

[29] D. Bascone, P. Angeli, E. S. Fraga, A modelling approach for the comparison between intensified extraction in small channels and conventional solvent extraction technologies, Chemical Engineering Science 203 (2019) $201-211$.

[30] J. M. Commenge, L. Falk, J. P. Corriou, M. Matlosz, Optimal design for flow uniformity in microchannel reactors, AIChE Journal 48 (2) (2002) $345-358$.

[31] F. Scheiff, M. Mendorf, D. Agar, N. Reis, M. Mackley, The separation of immiscible liquid slugs within plastic microchannels using a metallic hydrophilic sidestream, Lab on a Chip 11 (6) (2011) 1022-1029.

[32] D. Bascone, P. Angeli, E. S. Fraga, Mathematical modelling of intensified extraction for spent nuclear fuel reprocessing, Nuclear Engineering and Design 332 (2018) 162-172.

[33] J. M. Commenge, M. Saber, L. Falk, Methodology for multi-scale design of isothermal laminar flow networks, Chemical Engineering Journal 173 (2) (2011) 541-551.

[34] D. Bascone, P. Angeli, E. S. Fraga, Mathematical modelling of intensified extraction for spent nuclear fuel reprocessing, ), in: A. Espuña, M. Graells \& L. Puigjaner (Editors), Proceedings of the 27th European Symposium on Computer Aided Process Engineering - ESCAPE 27, Barcelona (Spain), 2017, pp. 355-360.

[35] N. Aoki, R. Ando, K. Mae, Gas-liquid-liquid slug flow for improving liquidliquid extraction in miniaturized channels, Industrial \& Engineering Chemistry Research 50 (8) (2011) 4672-4677. 
[36] B. Guillaume, J. P. Moulin, C. Maurice, Chemical properties of neptunium applied to neptunium management in extraction cycles of purex process, in: Extraction '84, Pergamon, 1984, pp. 31-45.

[37] D. Bascone, P. Angeli, E. S. Fraga, Optimal design of a coex process for spent nuclear fuel reprocessing using small channels, in: M. R. Eden, M. Ierapetritou and G. P. Towler (Editors), Proceedings of the 13th International Symposium on Process Systems Engineering - PSE 2018, San Diego (US), 2018, pp. 2365-2371.

[38] R. Geier, H. A. P. Operation, Application of the pulse column to the Purex process, Hanford Atomic Products Operation, 1957.

[39] R. Geier, L. Browne, Solvent extraction equipment evaluation study. part 1. review of the literature, Tech. Rep. BNWL-2186(PT.1), Battelle Pacific Northwest Labs., Richland, Wash. (USA) (January 1977).

[40] K. Gonda, T. Matsuda, Solvent extraction calculation model for PUREX process in pulsed sieve plate column, Journal of Nuclear Science and Technology 23 (10) (1986) 883-895.

[41] G. L. Richardson, J. L. Swanson, Plutonium partitioning in the purex process with hydrazine stabilized hydroxylamine nitrate, Tech. rep., Hanford Engineering Development Laboratory (1975).

[42] W. S. Groenier, Calculation of the transient behavior of dilute-purex solvent extraction process having application to the reprocessing of lmfbr fuels, Tech. rep., Oak Ridge National Laboratory (1972).

[43] R. Natarajan, N. K. Pandey, V. Vijayakumar, R. V. Subbarao, Modeling and simulation of extraction flowsheet for FBR fuel reprocessing, Procedia Chemistry 7 (2012) 302-308.

[44] T. Asakura, S. Hotoku, Y. Ban, M. Matsumura, Y. Morita, Technetium separation for future reprocessing, Journal of Nuclear and Radiochemical Sciences 6 (3) (2005) 271-274. 
[45] M. Benedict, T. H. Pigford, H. W. Levi, Nuclear Chemical Engineering 2nd Edition, McGraw Hill, New York, 1980.

[46] S. Kumar, S. B. Koganti, Modelling of Np(IV) and Np(VI) distribution coefficients in 30\% TBP/n-dodecane/nitric acid/water biphasic purex system, Indian Journal of Chemical Technology 8 (1) (2001) 41-43.

[47] G. Uchiyama, S. Hotoku, S. Fujine, Distribution of nitrous acid between tri-n-butyl phosphate/ n-dodecane and nitric acid, Solvent Extraction and Ion Exchange 16 (5) (1998) 1177-1190.

[48] S. Kumar, S. B. Koganti, Empirical modelling of U(IV) distribution in nitric acid-water-30\% TBP/n-dodecane biphasic system in presence of $\mathrm{U}(\mathrm{VI})$, $\mathrm{Pu}(\mathrm{III})$ and hydrazine nitrate, Nuclear Technology Vol. 123, No.1, 116-119, July'98 (1998).

[49] S. Kumar, S. B. Koganti, An empirical correlation for Pu(III) distribution coefficients in $30 \% \mathrm{TBP} / \mathrm{n}$-dodecane PUREX system in the presence of $\mathrm{U}(\mathrm{VI}), \mathrm{U}(\mathrm{IV}), \mathrm{Pu}(\mathrm{IV}), \mathrm{Pu}(\mathrm{III})$, and Hydrazine Nitrate, Solvent Extraction and Ion Exchange 21 (3) (2003) 369-380.

[50] C. Hongyan, R. J. Taylor, M. Jobson, A. J. Masters, Simulation of neptunium extraction in an advanced purex process-model improvement, Solvent Extraction and Ion Exchange 35 (1) (2017) 1-18.

[51] V. S. Koltunov, Kinetika reaktsii aktinoidov (Kinetics of Actinide Reactions), Atomizdat, Moscow, 1974.

[52] S. Tachimori, Extra-m: A computing code system for analysis of the purex process with mixer settlers for reprocessing, Tech. rep., Japan Atomic Energy Research Institute (1994).

[53] M. Pan, Y. Tang, L. Pan, L. Lu, Optimal design of complex manifold geometries for uniform flow distribution between microchannels, Chemical Engineering Journal 137 (2) (2008) 339-346. 
[54] R. E. Treybal, The economic design of mixer-settler extractors, AIChE Journal 5 (4) 474-482. 